\title{
The Pathogenicity of Bacillus anthracis Lysogenic with Mutants of Phage W
}

\author{
By G. IVÁNOVICS \\ Institute of Microbiology, Medical University, Szeged, Hungary
}

(Received 17 July 1961)

\begin{abstract}
SUMMARY
Mutants of phage $W$ with diverse virulence were used to lysogenize naturally occurring strains of Bacillus anthracis and their non-capsulogenic derivates. The temperate mutant $\beta$ readily established itself as a prophage in both sporogenous and non-sporogenous strains of $\boldsymbol{B}$. anthracis. Strains carrying $\beta$-prophage were stable, capable of giving rise to colonies, and their multiplication was not impaired in the mouse. Thus, the virulence of capsulogenic strains, lysogenic for phage $\beta$, was not diminished. A less temperate mutant of phage $W$, phage $\alpha$, was not capable of lysogenizing an atypical asporogenous strain of $\boldsymbol{B}$. anthracis, but formed more or less stable complexes with sporogenous strains. The stability of spores carrying phage genome $\alpha$ covered a wide range. Most of such spores did not give rise to colonies after germination but instead formed plaques. In some spores, however, phage $\alpha$ established itself as prophage so that stable lysogenic bacteria could be obtained under certain conditions. Spores of both capsulogenic and non-capsulogenic strains of $\boldsymbol{B}$. anthracis lysogenic for phage $\alpha$ formed the same number of either plaques or colonies when plated on a sensitive indicator strain or spread on agar surface. When, however, the spores were spread on agar containing $0.025 \mathrm{M}$-sodium bicarbonate and the plates incubated at a high partial pressure of $\mathrm{CO}_{2}$, then phage development in the lysogenic spores was induced. Hence, under these conditions, the lysogenic spores did not give rise to colonies but lysed and liberated phage. A small proportion of capsulogenic spores carrying prophage $\alpha$ threw off nonlysogenic segregants which gave rise to mucoid colonies in $\mathrm{CO}_{2}$. These mucoid colonies consisted of encapsulated bacteria which probably remained non-lysogenic because their capsules prevented re-infection during their growth. Capsulogenic strains carrying prophage $\alpha$ were markedly less virulent in the mouse and this may be explained by induction of $\alpha$-prophage by high $\mathrm{CO}_{2}$ tension in the animal body.

This competition between prophage induction and capsule formation, both of which were induced by high $\mathrm{CO}_{2}$ tension, explains the apparent diminution of the virulence of strains of $B$. anthracis lysogenic for $\alpha$-phage.
\end{abstract}

\section{INTRODUCTION}

MeCloy (1951) described a lysogenic strain of Bacillus cereus, named strain W, which liberates phage highly specific for $B$. anthracis. The temperate phage released by strain $W$ has been named $W \beta$ (abbreviated to $\beta$ ) and can lysogenize either typical or atypical strains of $B$. anthracis. A virulent mutant of phage $\beta$ named $W \alpha$ (abbreviated to $\alpha$ ) sometimes appeared in old cultures of $B$. cereus, strain $W$, which could form plaques on $B$. anthracis lysogenized by phage $\beta$. Phage $\alpha$ has a very low efficiency of plating on $B$. cereus strain $W$ after growth on 
any other host (Dr E. McCloy, personal communication). Most of McCloy's observations (McCloy, 1958) were nade on a host which is an atypical, asporogenous, strain of $B$. anthracis, strain D.ıvis. This strain was used to propagate and assay the phages and to provide lysogeric derivatives.

Capsule formation is essental for the virulence of Bacillus anthracis and noncapsulated avirulent mutants can easily be obtained from naturally occurring virulent strains of this species (Sterne, 1938). The colonial appearances of both capsulogenic and non-capsulogenic strains are similar on nutrient agar in air, but when the medium contains blood or serum and the plates are incubated in an atmosphere containing 5-25\% CO. (Sterne, 1937; Ivánovics, 1937) the colonies of capsulated strains are mucoid whereas those of non-capsulated mutants are still dry and irregular. In view of this remarkable difference between naturally occurring strains and their non-capsulogenic mutants, which is strictly correlated with their virulence for the mouse, a comparative study was made of lysogenic derivatives from both capsulogenic and non-capsulogenic mutants of $B$. anthracis. The main point was to determine the influence, if any, of lysogeny on the virulence of B. anthracis. It was found that the stability of lysogenic complexes was the determining factor in the pathogenicity of artificial lysogenic derivatives of this species.

\section{METHODS}

Bacteria. These are listed in Table 1. Strain Vollum and its non-proteolytic mutant, NPA, were obtained fron Dr H. Smith, Microbiological Research Establishment, Porton, Wiltshire. Strair 100 came from our own collection. The virulent strains were passed through mice at intervals to maintain their full virulence. When

Table 1. Bacterial strains used in the experiments

\begin{tabular}{lccc}
\multicolumn{1}{c}{ Strain } & Virulence & $\begin{array}{c}\text { Capsule } \\
\text { production* }\end{array}$ & $\begin{array}{l}\text { Designation } \\
\text { B. anthracis Vollum }\end{array}$ \\
$\begin{array}{lcc}\text { Derivate of VC+ } \\
\text { B. anthracis NPA }\end{array}$ & + & + & $\mathrm{VC}^{+}$ \\
Derivate of NPC+ & + & - & $\mathrm{VC}^{-}$ \\
B. anthracis 100 & - & + & $\mathrm{NPC}^{+}$ \\
\multicolumn{4}{c}{ * On buffered medium in the presence of $\mathbf{2 5} \% \mathrm{CO}_{2}$. }
\end{tabular}

mice were infected subcutaneousy, an inoculum of ten spores killed at least two thirds of the animals. Non-capsulogenic derivatives of wild strains were obtained according to Sterne's technique (Sterne, 1938). They were subcultured twice before being used. A dose of $10^{6}$ to $10^{7} \mathrm{~s}$ yores of the non-capsulogenic strains did not kill mice. The atypical asporogenous $B$. anthracis strain Davis, and its streptomycinresistant mutant, together with $B$. cereus strain $W$, were received from Dr McCloy. Strain Davis produces a capsule, but its virulence for mice is insignificant. The strains were maintained on YP ag: r. Strain Davis was subcultured every 4-5 days, and the spore-forming strains at 2 -monthly intervals.

Phages. Phage $\mathrm{W} \beta$ was isolated from an exponentially growing culture of Bacillus cereus strain W. A typical single plaque produced on strain Davis was propagated 
on strain Davis in liquid YP medium. The titre of the phage stocks was between $10^{9}$ and $10^{10}$ plaque-forming particles (p.f.p.)/ml. (on strain Davis).

Phage $W \propto$ was obtained from Dr McCloy in May 1956. The material provided had been grown on strain Davis, and consisted of a variant, $\alpha \mathbf{L}$, which produced large plaques on strains lysogenic with $\beta$ (McCloy, personal communication). Fresh phage preparations were made at 4-6 monthly intervals by propagation on strain Davis in liquid medium. Each new preparation was checked for homogeneity by plating on strains Davis and $\mathrm{VC}^{-}$; at a late stage in this investigation, a mutant of phage $\alpha$ appeared which could be distinguished from the original phage $\alpha$ by plating on $\mathrm{VC}^{-}$but not by plating on strain Davis. This mutant will be referred to as phage $\alpha \mathrm{C}$. Lysates were filtered through asbestos pads which had previously been washed several times. Six phage stocks had a mean titre of $2 \cdot 4 \times 10^{10} \pm 0 \cdot 45 \times 10^{10}$ p.f.p. $/ \mathrm{ml}$.

Antiserum to phage was obtained from hyperimmunized rabbits. Its neutralization rate constant, $\mathrm{K}$, at $37^{\circ}$ was $170 \mathrm{~min}^{-1}$.

Media. YP broth (yeast extract peptone medium) was prepared as described previously (Ivánovics \& Alföldi, 1955), and used routinely for growing bacteria and phage. Solid media contained $1.5 \%(\mathrm{w} / \mathrm{v})$ agar. YC (yeast extract casein hydrolysate) medium (Ivánovies \& Alföldi, 1955) solidified with $1.5 \%(\mathrm{w} / \mathrm{v})$ agar and containing $0.025 \mathrm{M}-\mathrm{NaHCO}_{3}$ was used to cultivate $B$. anthracis in the presence of $25 \% \mathrm{CO}_{2}$. A bicarbonate $/ \mathrm{CO}_{2}$ buffer system promotes capsule formation by B. anthracis (Thorne, Gomez \& Housewright, 1952). Cultivation in this way will be referred to below as $\mathrm{YC} / \mathrm{BB}$ (yeast casein medium in bicarbonate buffer).

Liquid cultures were grown in $20 \mathrm{ml}$. of medium in $100 \mathrm{ml}$. Erlenmeyer flasks, and were always aerated by gentle shaking. The optical density was read by inserting a side arm of the flask $16 \mathrm{~mm}$. in diameter into a photometer, and served to estimate the total count of the culture by means of the calibration curve described by Lantos, Varga \& Ivánovics (1960). The variable chain formation of individual strains and the variable chain length at different periods of growth did not allow the actual number of bacteria to be measured.

Spore suspensions. The bacteria were grown on YP agar, a heat-shocked $\left(80^{\circ}\right.$ for 5 min.) inoculum being used to ensure good sporulation of the culture, and the plates were incubated at $37^{\circ}$ for at least 4 days. The sporulated culture was then taken up with a loop into saline and the suspension was carefully homogenized. Centrifugation in a horizontal centrifuge at $100 \mathrm{~g}$ for $7 \mathrm{~min}$. deposited the heavier clumps consisting of large aggregates of spores and remnants of vegetative bacteria. The slightly turbid supernatant was carefully removed, and examined microscopically: usually $90-95 \%$ of the units were single spores, while the rest were small aggregates of only a few spores; in cases where the preparation contained a higher proportion of aggregates it was centrifuged a second time. Satisfactory suspensions were heated at $80^{\circ}$ for 5 min., which did not reduce the number of spores capable of germinating, but was sufficient to inactivate contaminating free phage particles.

Viable counts. $0.1 \mathrm{ml}$. volumes of appropriate dilutions of cultures or spore suspensions were spread on plates of YP medium which had been lightly dried and incubated at $37^{\circ}$ for $24 \mathrm{hr}$. Counts were also made in $\mathrm{YC} / \mathrm{BB}$, where capsulogenic strains produced mucoid colonies. With uninfected spores, the counts obtained on the two media were the same.

Phage assays. Great care was taken to standardize the bacterial inoculum with 
which the phage was plated, for this appreciably influenced the plaque morphology. YP broth was inoculated from a static culture incubated overnight at $25^{\circ}$ and the organisms grown at $37^{\circ}$ with a ration to an optical density of $0 \cdot 3.0 .5 \mathrm{ml}$. of the culture was mixed with $0.5 \mathrm{ml}$. of an appropriate dilution of the phage, $1 \mathrm{ml}$. of melted $1.5 \%(\mathrm{w} / \mathrm{v})$ YP agar was added and the whole was layered on a YP agar plate. Strain Davis was used as the indicator strain except where plaque morphology was examined on wild strains o: Bacillus anthracis or their non-capsulogenic derivatives. To assay free phage in t 1e presence of lysogenic bacteria, the streptomycinresistant mutant of strain Davi; was used as indicator on $50 \mu \mathrm{g}$. streptomycin $/ \mathrm{ml}$. agar.

Adsorption. 'To estimate the rate of adsorption, $4.5 \mathrm{ml}$. of exponentially growing bacterial culture with optical density $0 \cdot 3$ (equivalent to about $1 \cdot 6 \times 10^{8}$ organisms/ ml.) were mixed with $0.5 \mathrm{ml}$. of phage at a dilution giving a multiplicity of $0 \cdot 1-0 \cdot 3$. The mixtures were kept at $37^{\circ}$ for $20 \mathrm{~min}$. and then a $0.1 \mathrm{ml}$. sample added to $9.9 \mathrm{ml}$. chilled broth was centrifuged at $] 300 \mathrm{~g}$ in a cooled horizontal centrifuge for $15 \mathrm{~min}$., and the unadsorbed phage in the supernatant was assayed.

Isolation of lysogenic derivatives. The diverse responses of individual cells to temperate phage infection is well known (Lieb, 1953; Luria, Fraser, Adams \& Burrous, 1958). The responses of individual cells to phage infection cannot be studied with a chain-forming bacterium simply by plating infected suspensions, for in this case each colony consists o a mixture of the descendants of all those members of the chain which survived the infection. Mixed colonies of organisms carrying phage and organisms not carrying phage may arise thus. They may also occur by the segregation of non-lysogenic cels in a lysogenic clone; this happens especially frequently during the first few generations after lysogenization (Luria et al. 1958), but may also occur later. Instec d of attempting to analyse the colonies directly produced by an infected suspension, the growth which it produced was allowed to sporulate, and the colonies derived from individual spores were examined. By plating spore suspensions in whicl the spores were well dispersed, each colony could be regarded as the progeny of a single spore, and any heterogeneity in the colonies would be an expression of segregetion.

Artificially lysogenic strains we re isolated by adding phage at a multiplicity of $1-5$ to exponentially growing bacteria, and plating the mixture on YP agar after incubation at either $37^{\circ}$ or room tomperature for 10-30 min. In other cxperiments, exponentially growing cultures were infected with a low multiplicity of phage $(0 \cdot 01-0 \cdot 05)$ and incubated for $3-\xi ;$ hr. until the onset of lysis; the deposits after centrifugation were then plated. In either case, the plates were incubated at $37^{\circ}$ for at least 4 days; the spores wer : then harvested and treated as described above and the spore suspensions were plated to give well-separated colonies which were tested for immunity, lysogeny and shage-resistance by cross-streaking on phage and bacterium indicator plates. A stre $\mathrm{k}$ was made either with a loopful of phage containing $10^{7}-5 \times 10^{7}$ p.f.p. $/ \mathrm{ml}$., or with a suspension of strain Davis, and cross-streaked at right angles with suspensions of the individual colonies to be tested. The plates were read after overnight incubaticn at $37^{\circ}$. Lysogenic strains were immune to the homologous phage and gave a narnow zone of lysis with the bacterial indicator at the junction of the two streaks. When a colony was found not to be lysogenic although insensitive to the phage, it was considered to be a resistant mutant. 
The spore suspensions were, in addition, examined by plating in parallel on YP agar and $\mathrm{YC} / \mathrm{BB}$, and also plated with strain Davis in an overlay to determine the number which gave rise to plaques.

Induction of lysogenic strains by ultraviolet light. Ten $\mathrm{ml}$. of an exponentially growing culture in YP broth at optical density $0 \cdot 2\left(=7 \times 10^{7}\right.$ bacteria $/ \mathrm{ml}$. $)$ were placed in a Petri dish and irradiated with a low-pressure Hanau germicidal lamp. In most cases, $600-1200 \mathrm{ergs} / \mathrm{mm}^{2}$. was found to be the optimal dose for induction of the lysogenic complexes. Lysis of the irradiated cultures on reincubation was followed by measurements of optical density and also by assay of free phage using the streptomycin-resistant indicator and streptomycin agar.

Estimation of virulence of Bacillus anthracis strains. Spore suspensions of the strain to be tested were inoculated in to groups of mice. Virulence was expressed as the smallest number of spores which killed at least two-thirds of the mice inoculated. Usually this was about 10 spores; however, in exceptional cases, 100 spores were needed to kill the animals. 'Full virulence' implies that the lethal dose was $<100$ spores.

\section{RESULTS}

Plaque morphology, adsorption and efficiency of plating of phage $W$ on individual strains of Bacillus anthracis. McCloy (1958) gave a careful description of the plaques formed by the different mutants of phage $W$. As she found, recognition of the mutants $\alpha$ and $\beta$ by their plaque morphology is highly dependent on the medium used. A thick lawn of strain Davis is essential for mutant $\beta$ to form its characteristic 'target-like' plaques. The heavy growth which strain Davis produced on YP agar gave typical plaques of phage $\beta$, and phage $\alpha$ formed perfectly clear plaques: the plaque morphology indicates a difference in the virulence of these two phages for this atypical asporogenous strains of $B$. anthracis. The plaques of both mutants were c. 2.5-3 mm. diam.

The sporogenous strains of Bacillus anthracis gave thicker lawns than strain Davis, and the plaques differed somewhat in appearance on the different strains. On strains $\mathrm{VC}^{+}, \mathrm{VC}^{-}$and $100 \mathrm{C}^{+}$, the ring of growth in phage $\beta$ plaques was only slightly more transparent than the uninfected lawn so that it was not easy to recognize the boundary of the plaques by transmitted light; but by oblique light a shallow depression could be seen. The plaques were again $c .2 \cdot 5-3 \mathrm{~mm}$. diam. On strains $\mathrm{NPC}^{+}$and $\mathrm{NPC}^{-}$, phage produced minute $(<1 \mathrm{~mm}$. diam.) moderately clear plaques with a surrounding narrow depression.

As mentioned in the Methods, a mutant, $\alpha \mathrm{C}$, was obtained from the original phage $\alpha$ in the latter part of this investigation. On strain Davis, phage $\alpha$ and phage $\alpha \mathrm{C}$ both formed identical perfectly clear plaques, but on strains $\mathrm{VC}^{+}, \mathrm{VC}^{-}$and $100 \mathrm{C}^{+}$, while phage $\alpha \mathrm{C}$ still formed clear plaques, phage $\alpha$ formed plaques which were somewhat target-like in appearance. The structure of these plaques was faint; that is, only a small proportion of the bacteria did not lyse, but their hazy appearance contrasted with the perfectly clear plaques which phage $\alpha \mathrm{C}$ formed on these indicators. The plaques of phage $\alpha$ were $c .3 \mathrm{~mm}$. diam.; there were two mutants of $\alpha \mathrm{C}$ differing in plaque size: $3 \mathrm{~mm} .(\alpha \mathrm{Cl})$ and $<2 \mathrm{~mm}$. $(\alpha \mathrm{Cs})$.

On strains $\mathrm{NPC}^{+}$and $\mathrm{NPC}^{-}$phage $\alpha$ and phage $\alpha \mathrm{C}$ both formed small $(<1 \mathrm{~mm}$.) 
plaques which were transparent. The efficiencies of plating on strain $W$ of phages $\alpha$ and $\alpha \mathrm{C}$ (grown on strain Davis) were equally low $\left(10^{-5}\right.$ to $\left.10^{-6}\right)$, and both formed turbid plaques which were very heterogeneous in size on this strain.

The efficiency of plating of phage $\alpha$ was rather higher on strain Davis than on the other strains of Bacillus anthrcicis.

The adsorption rates of phage $\alpha$ to the different strains of $B$. anthracis were found to be about the same, and more than $95 \%$ of particles adsorbed under the conditions used. This is in contrast to the observations of McCloy (personal communication), who found poor adsorption to typical strains of $\boldsymbol{B}$. anthracis. Adsorption was also measured with suspensions of heavily encapsulated bacteria of strains $\mathrm{VC}^{+}$and $\mathrm{NPC}^{+}$obtainec from $\mathrm{YC} / \mathrm{BB}$, but there was no detectable decrease in free phage.

Table 2. Number of color y and plaque formers, and the virulence of four $\beta$ lysogenic isolat s obtained from strains $\mathrm{VC}^{+}$and $\mathrm{VC}^{-}$

\begin{tabular}{|c|c|c|c|c|c|}
\hline \multirow[b]{2}{*}{ Strain } & \multirow[b]{2}{*}{ Isolates } & \multicolumn{3}{|c|}{$\begin{array}{c}\text { Number of colony and plaque formers/ml. of spore } \\
\text { suspersion and the appearance of colonies under } \\
\text { different cultivation }\end{array}$} & \multirow[b]{2}{*}{ Virulence } \\
\hline & & YP aqar & YC/BB culture & In Davis & \\
\hline $\mathbf{V C}^{+}(\beta)$ & 1 & $4.0 \times 11^{7} \mathrm{R}$ & $3.4 \times 10^{7} \mathrm{M}$ & $3 \cdot 3 \times 10^{7} \mathrm{P}$ & Full \\
\hline $\mathbf{V C}^{+}(\beta)$ & 2 & $5 \cdot 7 \times 10^{7} \mathrm{R}$ & $5 \cdot 8 \times 10^{7} \mathrm{M}$ & $5 \cdot 6 \times 10^{7} \mathrm{P}$ & Full \\
\hline $\mathbf{V C}^{+}(\beta)$ & 3 & $5 \cdot 3 \times 11^{7} \mathrm{R}$ & $5.6 \times 10^{7} \mathrm{M}$ & $5 \cdot 4 \times 10^{7} \mathrm{P}$ & Full \\
\hline $\mathrm{VC}^{-}(\beta)$ & 1 & $1.8 \times 11^{7} \mathrm{R}$ & $1.8 \times 10^{7} \mathrm{R}$ & $1.7 \times 10^{7} \mathrm{P}$ & None \\
\hline
\end{tabular}

Explanation: $\mathbf{R}=$ typical $\mathbf{R}$ form of colony; $M=$ mucoid colony; $P=$ plaques.

$\mathbf{Y P}=\mathbf{Y P}$ agar in $:$ ir $; \mathrm{YC} / \mathrm{BB}=\mathrm{YC}$ buffered agar in the presence of $\mathrm{CO}_{2} ;$ In Davis = plaques formed in indicator strain Davis.

Strains lysogenic with $\beta$. In accordance with McCloy's observations, strains could easily be lysogenized with phage $\beta$. The characteristics of $\mathrm{VC}^{+}$and $\mathrm{VC}^{-}$lysogenized with $\beta$ are summarized in Table 2 . The colonies of the lysogenic derivatives could not be distinguished from those of the parent strain, and the virulence of lysogenic spores did not change. Similar observations were made when strains $\mathrm{NPC}^{+}, \mathrm{NPC}^{-}$ and $100 \mathrm{C}^{+}$lysogenized by plage $\beta$ were tested. The lysogenic complexes were stable: only lysogenic bacteriı were isolated from mice dead of infection with lysogenic derivatives of a virulent strain. Nor did growth in $\mathrm{YC} / \mathrm{BB}$ cause a loss of the prophage, thus the formation of the capsule and the stability of the prophage could exist concomitantly. A nutation in the genome of $B$. anthracis which results in the loss of capsule produstion has thus no influence on the stability of prophage $\beta$. When non-capsulogenic mutants were isolated by Sterne's (1938) method from lysogenic wild strains, neither induction nor loss of the prophage was observed.

Prophage $\beta$ also showed considerable stability when exponentially growing lysogenic bacteria were irradiated with ultraviolet light. Only a 300-fold increase of phage was found when strair $\operatorname{VC}^{+}(\beta)$ was irradiated and assayed for phage after re-incubation for $6 \mathrm{hr}$. This is a s omewhat greater increase than that found by McCloy (1958) after ultraviolet induction of the naturally lysogenic B. cereus strain W, or than we observed when we tested this strain. 
The phage liberated by typical Bacillus anthracis strains or by their non-capsulogenic mutants after lysogenization with $\beta$ produced plaques identical in appearance to those produced by the phage from lysogenic Davis. The efficiency of plating of phage $\alpha$ on $\mathrm{VC}^{-}(\beta)$ was about half that on non-lysogenic $\mathrm{VC}^{-}$.

Lysogenization with phage $\alpha$. Phage $\alpha$ does not establish lysogeny in the atypical strain of Bacillus anthracis, strain Davis. McCloy (1958) has reported that a proportion of the spores of a typical strain of $B$. anthracis (1444) formed in the presence of phage $\alpha$ were lysogenic with $\beta$; she assumed that phage $\beta$ had arisen during growth of phage $\alpha$ in this strain. Also, spores of this strain, and of B. cereus strain $W$, formed in the presence of phage $\alpha$ could contain phage $\alpha$ in a heat stable form: suspensions of such spores produced plaques and phage-free colonies. Individual spores never produced both phage $\alpha$ and a colony (McCloy, 1953).

Although all our attempts to obtain a derivative of strain Davis lysogenic with phage $\alpha$ failed, the plaque morphology of this variant on sporogenous strains encouraged us to try to isolate lysogenic derivatives of these strains. We succeeded in isolating lysogenic complexes of phage $\alpha$ and strains $\mathrm{VC}^{+}, \mathrm{VC}^{-}, \mathrm{NPC}^{+}, \mathrm{NPC}^{-}$and $100^{+}$, but the occurrence of these lysogenic derivatives appeared to vary in individual experiments. During more than 2 years, in more than 20 experiments, several hundred clones isolated after exposure to phage $\alpha$ were tested for lysogeny and immunity, but only a few dozen stable lysogenic isolates were found: of these, three were lysogenic with $\beta$, and the rest carried prophage $\alpha$. The experiments gave variable results for reasons so far unknown. Chloramphenicol treatment of the bacteria before infection with phage did not increase lysogeny. It was found, however, that repeated replating of the colonies surviving phage $\alpha$ infection could lead to the isolation of stable lysogenic strains, but in some experiments the unstable lysogenic complexes gradually disappeared on serial subculture and no lysogenic isolates were finally recovered. The success in obtaining stable lysogenic complexes when non-capsulogenic or capsulogenic strains were used for lysogenization cannot be expressed numerically. Clearly, however, it was much easier to isolate stable lysogenic derivatives with phage $\alpha$ when non-capsulogenic strains were used.

Non-capsulogenic strains lysogenized by phage $\alpha$. The following experiment demonstrates the isolation of a lysogenic derivative of a non-capsulogenic strain. Exponentially growing cultures of $\mathrm{VC}^{-}$and $\mathrm{NPC}^{-}$containing $2 \cdot 6 \times 10^{8}$ bacteria $/ \mathrm{ml}$. were each infected with phage $\alpha$ at a multiplicity of infection of $0 \cdot 1$ and re-incubated for $8 \mathrm{hr}$. at room temperature. The cultures were then centrifuged and the deposits plated on YP agar. Some of the colonies appeared normal while others were irregular and eroded. Several were checked for lysogeny by cross-streaking and also subcultured and incubated for several days to allow sporulation. The heated spores produced approximately equal numbers of colonies and plaques. When these individual colonies were tested for lysogeny and immunity, 8/10 were found to be lysogenic and immune in the case of strain $\mathrm{NPC}^{-}$, and 10/10 in the case of strain $\mathrm{VC}^{-}$. Some of these lysogenic isolates were maintained by serial transfer on agar slopes for several months or longer, and their spore population was examined at intervals by simultaneously plating suspensions on YP agar, on strain Davis and in $\mathrm{YC} / \mathrm{BB}$ medium. In these assays, an unambiguous result was obtained with all the isolates: the numbers of colonies on YP agar and of plaques on Davis were equal, but the spores gave no colonies in $\mathrm{YC} / \mathrm{BB}$ (Table 3). The same result was obtained 
with fifteen different lysogenic isolates of lysogenic $\mathrm{VC}^{-}$and $\mathrm{NPC}^{-}$. When a heavy inoculum consisting of several tens of thousands of spores was inoculated, a few irregular colonies less than $1 \mathrm{~mm}$. diam. developed. Microscopic examination of these small colonies revealed thit most of the bacteria were lysed and that much granular bacterial debris was prisent.

Table 3. Number of colony and plaque formers per ml. of non-capsulogenic strains of Bacillus anthracis lysogenic with phage $\alpha$ and that of a non-lysogenic spore material

\begin{tabular}{|c|c|c|c|}
\hline \multirow[b]{2}{*}{ Strain } & \multicolumn{2}{|c|}{ Numl er of colony formers $/ \mathrm{ml}$. } & \multirow{2}{*}{$\begin{array}{l}\text { No. of plaque } \\
\text { formers/ml. } \\
\text { in Davis }\end{array}$} \\
\hline & YP agır & YC/BB culture & \\
\hline $\mathrm{VC}^{-}(\alpha)$ & $1 \cdot 2 \times 1)^{7}$ & $<10^{2 *}$ & $1.5 \times 10^{7}$ \\
\hline $\mathrm{NPC}^{-}(\alpha)$ & $2.5 \times 1)^{2}$ & $<5.0 \times 10^{4} \dagger$ & $3.0 \times 10^{7}$ \\
\hline $\mathrm{NPC}^{-}$ & $1.8 \times 111^{7}$ & $2 \cdot 0 \times 10^{7}$ & No plaques \\
\hline
\end{tabular}

* $12 \times 10^{3}$ and $\dagger 5 \times 10^{3}$ spures respectively did not give rise to colonies.

These observations suggested th at spores lysogenic with phage $\alpha$ lysed instead of forming colonies when they wer: cultivated in $\mathrm{YC} / \mathrm{BB}$ and, indeed, when the $\mathrm{YC} / \mathrm{BB}$ plates were washed with a few $\mathrm{ml}$. of water large numbers of phage particles were found in the washings. After the washings had been heated to $80^{\circ}$ for $5 \mathrm{~min}$. they produced no colonies on YP agar, indicating that all the viable spores had germinated. In one experiment, it was estimated that each spore inoculated on to YC/BB had given rise to 1000 phige particles, but the actual yield of phage was probably even higher, for in reconstruction experiments made with free phage, only about $20 \%$ of the phage put on the plates was recovered.

Induction was also observed when vegetative cells instead of spores were cultivated in $\mathrm{YC} / \mathrm{BB}$. Induction by $\mathrm{CO}_{2}$ was also seen with $\mathrm{YC}$ agar containing $20 \%(\mathrm{v} / \mathrm{v})$ bovine serum or $5 \%(\mathrm{v} / \mathrm{v})$ sheep blood in place of sodium bicarbonate. Some preliminary attempts were made to in luce lysogenic bacteria by $\mathrm{CO}_{2}$ when they were growing exponentially in liquid media, but no lysis of cells or liberation of phage was observed.

The lysogenic complexes of phą̧e $\alpha$ with non-capsulogenic strains of Bacillus anthracis were higly inducible by ultraviolet irradiation. Fig. 1 shows the results of an experiment made with strain $\mathrm{VC}^{-}$. The irradiation caused mass lysis of the cells

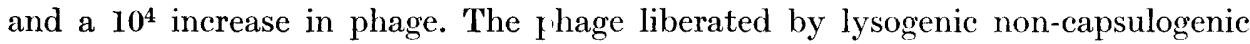
strains did not differ from the original phage $\alpha$ preparations grown on strain Davis: it formed perfectly clear plaques on strain Davis and the characteristic hazy plaques on strain $\mathrm{VC}^{-}$, with a small proportion $\left(c .10^{-3}\right)$ of clear plaques characteristic of phage $\alpha \mathrm{C}$. It had an efficiency of plating of $10^{-5}$ to $10^{-6}$ on $B$. cereus strain $W$ and an efficiency of plating of $0 \cdot 1-0 \cdot 5$ on Davis $(\beta)$ and $\mathrm{VC}^{-}$. It lysogenized strain $\mathrm{VC}^{-}$at the same low rate as the original phi ge.

The response of capsulogenic strains to phage $\alpha$. Stable lysogenic derivatives of the sporogenous capsulogenic strains were isolated using phage grown on strain Davis. Lysogeny with phage $\alpha$ was not readily established in these strains; although a large proportion of the spores formed in the presence of phage $\alpha$ gave rise to plaques, few gave rise to colonies.

When bacteria infected with phage $x$ were plated on $\mathrm{YC}$ agar and incubated with 
additional $\mathrm{CO}_{2}$, no stable lysogenic complexes could be isolated. The bacterial chains gave rise to mucoid colonies which consisted of non-lysogenic phage-sensitive organisms. When a heavy suspension of bacteria infected at a multiplicity of 1-2 was injected into mice, the cultures obtained from the blood after death did not contain either phage or lysogenic bacteria. This is in contrast to the result with suspensions of bacteria infected with phage $\beta$ where the bacteria recovered from the animals were all lysogenic.

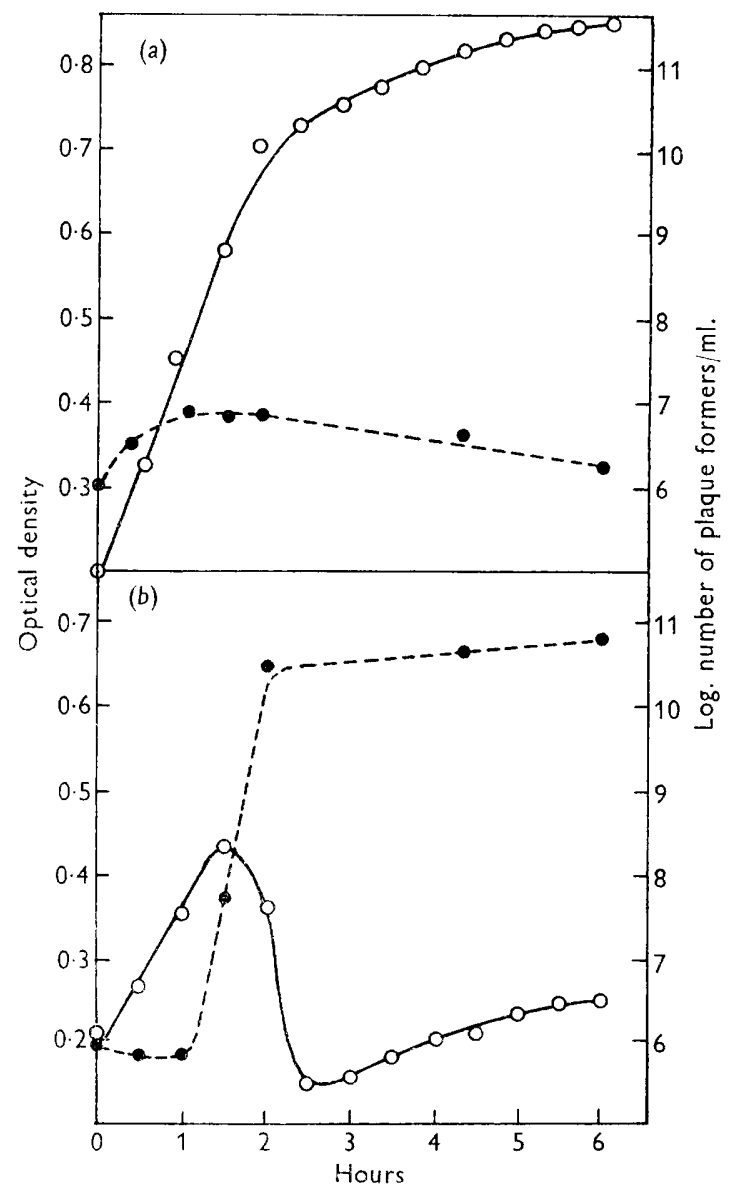

Fig. 1. Phage liberation by a $\mathrm{VC}^{-}(\alpha)$ /isolate. (a) Non-irradiated culture. (b) Irradiated at $0 \mathrm{hr}$. Solid lines $=$ optical density; dotted line $=$ number of phage particles.

The individual colonies which developed on YP agar from inocula infected with phage $\alpha$ were examined after sporulation. The spore populations consisted of individuals which either (1) lysed on plating, giving plaques but no colonies, (2), gave rise to colonies of non-lysogenic phage-sensitive bacteria, or (3) gave rise to a mixed population of stably lysogenic and non-lysogenic spores. In the case of the mixed colonies, it was not uncommon to find that some unstable lysogenic bacteria had lysed and that part of the colony was eroded. Stable lysogenic colonies could be selected by repeatedly subculturing a heterogeneous population of spores as shown 
in the following experiments (Fig. 2). It will be observed that with spore material $b$ which was lysogenic, only a proportion of 0.0002 spores gave rise to colonies in $\mathrm{YC} / \mathrm{BB}$ : five of these mucoid colınies were tested and all were found to be nonlysogenic and phage-sensitive.

The virulence of the stable lysoc enic isolate was tested, and it was found that $10^{4}$ spores did not kill but that with $10^{6}$ spores the mice died of anthrax. Bacteria recovered from the heart blood of these animals were found to be fully virulent and also to be non-lysogenic.

Suspension of $\mathrm{VC}^{+}+$phage $\alpha$ (multiplicity of infection $=0 \cdot 2$ ) plated on YP aq ar to allow sporulation

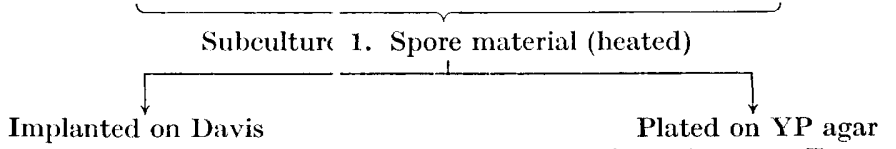

$3 \times 10^{6 *}$ clear plaques

$2 \cdot 2 \times 10^{6}$ colony formers. Two colonies were found to be lysogenic by cross streaks out of 20 colonies tested

Subculture 2. Two individuel phage carrier colonies subcultured and spore material obtained from each culture

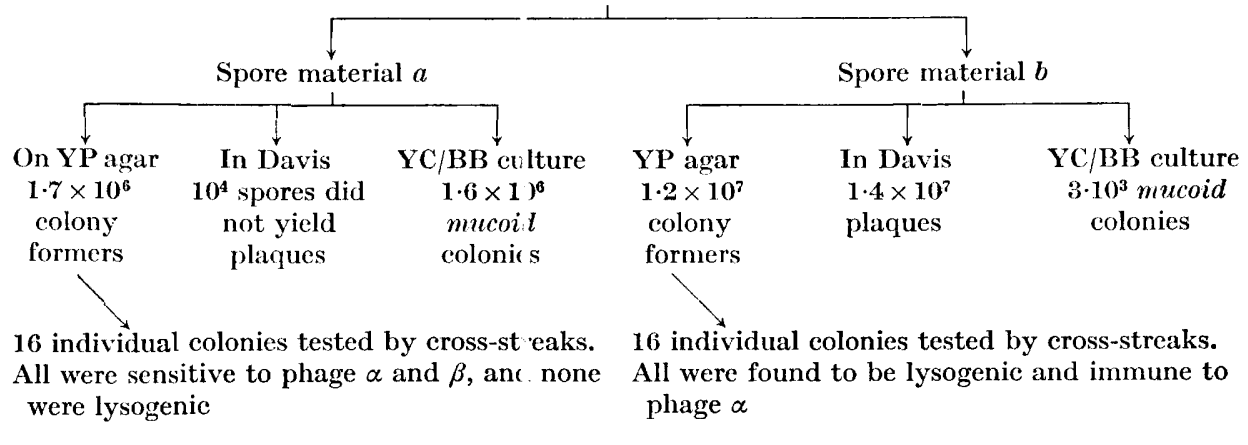

* The figures represent the number of colony and plaque formers respectively/ml. of heated spore material.

Fig. 2. Scheme of an e tperiment to obtain $\alpha$-lysogenic isolates.

Twelve stable isolates lysogenized with phage were kept for detailed study. Two of these were lysogenic with $\beta$, while the others carried prophage $\alpha$. Two of the latter, 52 and $8 \cdot 127$, although obt:ined from a virulent capsulogenic strain, did not kill mice even in enormous doses; and when plated in $\mathrm{YC} / \mathrm{BB}$ gave only non-mucoid colonies. It seems likely in this case that non-capsulogenic variants had been lysogenized, since these arise moderately frequently (Chu, 1952) and are more readily lysogenized by phage $\alpha$ tian capsulogenic bacteria. Of several hundred colonies tested for lysogeny and phage sensitivity, only one was resistant to phage without being lysogenic. This pha ge-resistant mutant was fully virulent and each spore gave rise to a mucoid colony in $\mathrm{YC} / \mathrm{BB}$.

Characteristics of isolates lysogenic with phage $\alpha$. The results of a detailed study of 10 isolates lysogenic with phage $\alpha$ are summarized in Table 4 . The virulence of the lysogenic derivatives was also test $\mathrm{d}$ in most cases by injecting $10^{3}-10^{4}$ spores into groups of mice. Practically all thes e animals survived. Mice dying of anthrax after 
injection with $10^{6}$ spores were evidently killed by non-lysogenic bacteria, for the strains recovered from their blood were either completely free of phage or only a small proportion of the spores gave rise to plaques. The non-lysogenic strains which were recovered from the animals which died were fully virulent.

Table 4. Characters of 10 isolates lysogenic with phage $\alpha$

\begin{tabular}{|c|c|c|c|c|c|c|c|}
\hline \multirow[b]{2}{*}{$\begin{array}{c}\text { Isolate } \\
\text { no. }\end{array}$} & \multirow[b]{2}{*}{$\begin{array}{c}\text { Strain } \\
\text { used } \\
\text { for } \\
\text { lyso- } \\
\text { genization }\end{array}$} & \multirow{2}{*}{$\begin{array}{c}\text { Colony } \\
\text { formers/ml. } \\
\text { of heated } \\
\text { spore } \\
\text { suspension } \\
\text { on YP } \\
\text { agar* }\end{array}$} & \multicolumn{2}{|c|}{$\mathbf{Y C} / \mathbf{Y B}$ cultures } & \multirow{2}{*}{$\begin{array}{c}\text { Plaque } \\
\text { formers } / \mathrm{ml} \text {. } \\
\text { of heated } \\
\text { spore } \\
\text { suspension } \\
\text { on strain } \\
\text { Davis }\end{array}$} & \multirow{2}{*}{$\begin{array}{c}\text { Mice } \\
\text { killed } \\
\text { by } \\
1 \times 10^{6} \\
\text { spores }\end{array}$} & \multirow{2}{*}{$\begin{array}{c}\text { Lysogeny } \\
\text { of } \\
\text { bacteria } \\
\text { re-iso- } \\
\text { lated } \\
\text { from } \\
\text { mice }\end{array}$} \\
\hline & & & $\begin{array}{l}\text { No. of } \\
\text { colony } \\
\text { formers }\end{array}$ & $\begin{array}{l}\text { Fraction } \\
\text { of spores } \\
\text { forming } \\
\text { colonies }\end{array}$ & & & \\
\hline $8 \cdot 132$ & $\mathbf{V C}^{+}$ & $1.2 \times 10^{7}$ & $3 \times 10^{3} \mathrm{M} \dagger$ & $0 \cdot 0002$ & $1 \cdot 4 \times 10^{7}$ & $3 / 4$ & - \\
\hline $8.51 \mathrm{~B}$ & $\mathrm{VC}^{+}$ & $4 \times 10^{6}$ & $<10^{4}$ & $<0.002$ & $3.6 \times 10^{6}$ & $1 / 3$ & - \\
\hline $\mathbf{K}$ & $\mathrm{VC}^{+}$ & $1.3 \times 10^{7}$ & $3 \times 10^{5} \mathrm{M}$ & 0.0025 & $0.9 \times 10^{7}$ & $3 / 3 \$$ & \pm \\
\hline $48 / 5$ & $\mathrm{VC}^{+}$ & $5.5 \times 10^{6}$ & $7 \times 10^{2} \mathrm{M}$ & 0.00015 & $4.4 \times 10^{6}$ & $1 / 3$ & $=$ \\
\hline 52 & $\mathrm{VC}^{+}$ & $3.4 \times 10^{7}$ & $8 \times 10^{2} \mathrm{NM}$ & $0 \cdot 00002$ & $4.0 \times 10^{7}$ & $0 / 3$ & . \\
\hline $8 \cdot 127$ & $\mathrm{NPC}^{+}$ & $1 \cdot 6 \times 10^{7}$ & $3 \times 10^{3} \mathrm{NM}$ & $0 \cdot 0002$ & $1.6 \times 10^{7}$ & $0 / 3$ & . \\
\hline $8 \cdot 42$ & $\mathrm{NPC}^{+}$ & $1.2 \times 10^{7}$ & $7 \times 10^{3} \mathrm{M}$ & 0.0006 & $0.9 \times 10^{7}$ & $2 / 3$ & - \\
\hline 2 & $100 \mathrm{C}^{+}$ & $5.5 \times 10^{5}$ & $8 \cdot 6 \times 10^{2} \mathrm{M}$ & $0 \cdot 0015$ & $5.0 \times 10^{6}$ & $1 / 3$ & \pm \\
\hline 5 & $100 \mathrm{C}^{+}$ & $5 \cdot 5 \times 10^{6}$ & $8 \times 10^{3} \mathrm{M}$ & $0 \cdot 0015$ & $4.8 \times 10^{6}$ & $3 / 3$ & - \\
\hline 19 & $100 \mathrm{C}^{+}$ & $4 \cdot 7 \times 10^{6}$ & $6 \cdot 3 \times 10^{2} \mathrm{M}$ & $0 \cdot 00014$ & $4.9 \times 10^{8}$ & $2 / 3$ & - \\
\hline
\end{tabular}

* Six to twelve individual colonies on YP agar checked for both lysogeny and immunity to phage $\alpha$. All colonies of individual isolates were found to be lysogenic and immune.

$\dagger \mathbf{M}=$ mucoid colonies; $\mathbf{N M}=$ non-mucoid colonies (but irregular $\mathbf{R}$ form of colonies were seen).

$\ddagger$ Several thousands of spores of cultures recovered from mice dead of anthrax were tested for lysogeny by incorporating them into sensitive indicator lawn. - ; no lysogenic spores were found; \pm , few plaques appeared.

$\$$ Less than 100 spores of the strains recovered from heart blood of mice dead of anthrax were found to kill in virulence test.

The spore suspensions of the lysogenic isolates produced nearly the same numbers of plaques and colonies on YP agar (Table 4). (Isolate 2, whose growth was abnormally slow, produced more plaques.) Since the colonies were lysogenic, this suggests that each spore was able to give rise to either a colony or a plaque depending on how it was plated. In contrast, only a very small proportion ( $1 / 400$ 1/7000) of the spores produced a colony on YC agar in an atmosphere with added $\mathrm{CO}_{2}$. The mucoid colonies which developed in $\mathrm{YC} / \mathrm{BB}$ could be classified as large or small; after $2 . \mathrm{hr}$. incubation, the former had a diameter of $c .3 \mathrm{~mm}$. and the latter a diameter of $<\mathbf{1 - 1 . 5} \mathrm{mm}$. The bacteria from large colonies were non-lysogenic and phage-sensitive, while inocula from small colonies contained a few phage-carrier bacteria as well as phage-free, phage-sensitive ones. One of the large non-lysogenic mucoid colonies was tested for virulence after a subculture had been allowed to sporulate on YP agar. Its virulence resembled that of the original strain, which suggested that the decrease in virulence of the lysogenic derivative was not due to a genotypic change in the bacteria but rather to a phenotypic expression of the presence of prophage $\alpha$.

The low virulence of the lysogenic derivatives appeared to be connected with the lability of the phage-bacterium complexes. Germination of lysogenic spores in the body was followed by induction of the prophage and resulted in lysis of the bacterium: 
only a few non-lysogenic segregarts escaped lysis. The animals were killed by these non-lysogenic segregants which were the bacteria recovered from the blood after death.

Identification of the prophage in strains lysogenized by phage $\alpha$. While a strain lysogenic with $\beta$ was still sensitive to phage $\alpha$, a strain lysogenic with $\alpha$ was immune to this phage (Table 5). The latter was also partially immune to phage $\alpha \mathrm{C}$. The phage liberated by the lysogenic k acteria, after induction with ultraviolet light, was similar to the phage preparation originally used to lysogenize the strain, hence when phage enters the prophage state in sporogenous bacteria, phage particles with greater ability to lysogenize do n'st appear to be selected. However, a mutation of phage $\alpha$ to phage $\beta$ may also occur' during the isolation of stable lysogenic complexes for, as McCloy (1958) also found, a few clones lysogenic with $\beta$ were present among those artificially lysogenized by , hage $\alpha$.

Table 5. Action of phage $\alpha$ ana $\beta$ on strain $V C^{+}$and on its lysogenic derivatives

\begin{tabular}{lccc}
\multirow{3}{*}{ Strain } & $\begin{array}{c}\text { Phage } \\
\text { particles* }\end{array}$ & $\overbrace{\alpha}$ & $\beta$ \\
$\mathrm{VC}^{+}$ & $10^{6}$ & ++ & ++ \\
& $10^{4}$ & ++ & ++ \\
\multirow{3}{*}{$\mathrm{VC}^{+}(\beta)$} & $10^{2}$ & ++ & ++ \\
& $10^{6}$ & ++ & - \\
& $10^{4}$ & ++ & - \\
$\mathrm{VC}^{+}(\alpha)$ & $10^{2}$ & + & - \\
& $10^{6}$ & - & - \\
& $10^{4}$ & - & -
\end{tabular}

* Approximate number of phage particles dropped on the smears of spore suspension of the strain tested.

$++=$ confluent lysis. $+=$ isolat $d$ plaques. $-=$ no plaques.

When spores of strains lysogenic with $\alpha$ were plated with strain Davis, clear plaques without any central colony were seen, similar to those produced by free phage particles. Occasionally, however, beside these clear plaques, turbid plaques appeared, some of which contained a few clear spots which gave the plaque a starlike appearance. When samples aken from these turbid plaques were plated with strain Davis, all the plaques ware quite clear, so it could be inferred that the atypical plaque morphology was merely a different phenotypic appearance of phage $\alpha$. The change in phenoty pe may have been caused by host-modification in the lysogenic bacteria.

Attempts to lysogenize with phige $\alpha \mathrm{C}$. A number of unsuccessful attempts were made to obtain stable lysogenic somplexes with phage $\alpha \mathrm{C}$. Both capsulogenic and non-capsulogenic strains were used. When cultures were exposed to phage $\alpha \mathrm{C}$ and plated, only a few thin irregulir transparent colonies appeared after overnight incubation. With longer incubation, the bacterial growth became somewhat thicker and contained spores. These spcres after heating gave rise to plaques and a small number of colonies. Most of the colonies were either eroded by lysis or else did not 
contain phage-carrier spores. With repeated subculture of partially eroded colonies, fewer and fewer eroded colonies were seen, and eventually even the unstable phagebacterium complexes disappeared.

\section{DISCUSSION}

McCloy (1958) failed to obtain stable lysogenic derivatives with phage $W \alpha$ and therefore considered this mutant to be incapable of lysogenizing. Lwoff (1953) pointed to the existence of intermediates between the extreme virulent and the typically temperate phages, and it was later learned that some representative 'virulent' phages, like 'T3, gave rise to complexes which divided and threw off uninfected segregants before lysis (Fraser, 1957). It was supposed that the complexes represented infected cells in a prelysogenic state. According to our observations, there is a gradual increase in the virulence of the different mutants of phage $W$. It appears that the genome of each mutant, i.e. $\beta, \alpha$ and $\alpha \mathrm{C}$, of phage $\mathrm{W}$ is able to form a more or less stable complex with the bacterium. Phage $\beta$ readily established itself as prophage in either a typical or atypical strain of Bacillus anthracis. The technical difficulties with a chain-forming bacterium did not permit a quantitative analysis of the rate of lysogenization, but there was clearly a high rate of lysogenic response. No difference was found between capsulogenic and non-capsulogenic strains, thus the genetic locus determining capsule production is independent of the acquisition of prophage $\beta$. Mutation of a lysogenic capsulogenic bacterium to the non-capsulogenic state was not accompanied by loss of prophage $\beta$. The virulence of a bacterium is not influenced by the presence of this prophage.

In the case of phage $\alpha$, the bacteria tend not to exhibit a lysogenic response; a small proportion survive infection, and these give rise to progeny in very unstable association with the phage. There is also a high rate of segregation of uninfected bacteria, which usually outnumber those in which the incorporated phage genome persists. It should, however, again be stressed that the present analyses were made exclusively with spores.

McCloy (1958) found spores lysogenic with prophage $\beta$ when bacteria had been allowed to sporulate in the presence of phage $\alpha$. We also found that a proportion of the lysogenic isolates carried prophage $\beta$, but most of them carried the prophage of $\alpha$ itself. Most of the spores which had incorporated the $\alpha$ genome lysed after germination and produced a plaque when plated with indicator bacteria; some, however, could give rise to colonies which yielded a mixture of spores each of which was either free of phage or carrying phage in an unstable prophage form. It is known that the 'decision' to spore is made long before the spore can be detected, and sporulation can be regarded as an endogenous mechanism which occurs after the completion of the spore precursors (Hardwick \& Foster, 1952; Roth, Lively \& Hodge, 1955). The extreme lability of the complexes with phage $\alpha$ formed during sporulation suggests that the phage genome after entering bacteria which are on the way to sporulation is not immediately reduced to prophage, but preserved as preprophage. The critical events determining whether the phage genome will multiply vegetatively or become prophage are thus postponed to the time of germination. The latent phage genome undergoes vegetative multiplication in a high proportion of germinating spores, and these are lysed. In others, it is reduced to prophage, or it may be diluted out during subsequent bacterial divisions, which therefore lead to a phage-free progeny. 
The most remarkable feature of $\alpha$-lysogenic complexes is their high inducibility. Ultraviolet irradiation causes total lysis of the cultures with liberation of several hundred times more phage than occurs with strains lysogenic with $\beta$. The nature of the prophage makes a striking difference to the fate of the bacteria when they are grown in an atmosphere with added $\mathrm{CO}_{2}$. A strain of Bacillus anthracis whether capsulogenic or non-capsulogenic, which is lysogenic with $\beta$ gives rise to equal numbers of colonies whether $\mathrm{CO}_{2}$ is added or not. Accordingly, capsulogenic strains lysogenic with $\beta$ preserve their original virulence for the mouse. On the other hand, only a small proportion of the bacteria lysogenic with $\alpha$ can give rise to colonies at high $\mathrm{CO}_{2}$ pressure, since most of them lyse following induction of vegetative phage multiplication. Induction was also observed on blood agar plates: the presence of catalase in this medium therefore excludes a potential role of peroxide accumulation as an inducing agent at high partial pressures of $\mathrm{CO}_{2}$. As would be expected from this finding, the virulence of spores lysogenic with $\alpha$ is very markedly diminished for the mouse, in which the $\mathrm{CO}_{2}$ tension is greater than in air. Both in vitro and in vivo, only non-lysogenic segregants are capable of giving rise to capsulated bacteria and killing mice, since capsulation is expressed only in the presence of a high concentration of $\mathrm{CO}_{2}$ (Sterne, 1937; Ivánovics, 1937). One may suppose that a block in the synthesis of the D-glutamic acid polymer forming the capsule of $\boldsymbol{B}$. anthracis (Ivánovics \& Bruckner, 1937) is released by $\mathrm{CO}_{2}$, and that this same block may play a role in the stabilization of $\alpha$ as prophage. The effect is independent of the gene determining the ability to produce the capsule, for loss of the ability to form the capsule occurring by mutation $\left(\mathrm{C}^{+} \rightarrow \mathrm{C}^{-}\right)$is not associated with loss of inducibility of prophage $\alpha$ by $\mathrm{CO}_{2}$.

The author is greatly indebted to Dr Elinor W. McCloy (The Wright-Fleming Institute of Microbiology, London) for her advice and help in preparing the manuscript, and for the phage material used in the experiments. Acknowledgement is due to Dr H. Smith (Ministry of Supply, Microbiological Research Establishment, Porton) for the strains of Bacillus anthracis.

\section{REFERENCES}

CHU, P. (1952). Variation of Bacillus anthracis with special reference to the non-capsulated avirulent variant. J. Hyg., Camb. 50, 433.

Fraser, D. K. (1957). Host range mutants and semitemperate mutants of bacteriophage T3. Virology, 3, 527 .

Hardwick, W. A. \& Foster, J. W. (1952). On the nature of sporogenesis in some aerobic bacteria. J. gen. Physiol. 35, 907.

IvíNovics, G. (1937). Unter welchen Bedingungen werden bei der Nährbodenzüchtung der Milzbrandbazillen Kapseln gebildet? Zbl. Bakt. 1. Abt. Orig. 138, 449.

Ivánovics, G. \& Alföldi, L. (1955). Observation on lysogenesis in B. megaterium and on megacin, the antibacterial principle of this Bacillus species. Acta microbiol. acad. Sci. hung. 2, 275.

Ivánovics, G. \& Bruckner, V. (1937). Chemische und immunologische Studien über den Mechanismus der Milzbrandinfektion und Immunität. I. Mitteilung. Die chemische Struktur der Kapselsubstanz des Milzbrandbazillus und der serologisch identischen spezifischen Substanz des Bacillus mesentericus. Z. ImmunForsch. 90, 304.

Lantos, J., Varga, I. \& Ivánovics, G. (1960). Characterization of anthrax phages. Acta microbiol. acad. Sci. hung. 7, 31. 
LIEB, M. (1953). 'The establishment of lysogenicity in Escherichia coli. J. Bact. 65, 642.

Luria, S. E., Fraser, D. K., Adams, J. N. \& Burrous, J. W. (1958). Lysogenization, transduction, and genetic recombination in bacteria. Cold Spr. Harb. Symp. quant. Biol. $23,71$.

LwofF, A. (1953). Lysogeny. Bact. Rev. 17, 269.

McCloy, E. W. (1951). Studies on a lysogenic Bacillus strain. I. A bacteriophage specific for Bacillus anthracis. J. Hyg., Camb. 49, 114.

McCloy, E. W. (1953). Sporulation of bacteria despite infection by virulent phage. Proc. 6th int. Congr. Microbiol. 3, 49.

McCloy, E. W. (1958). Lysogenicity and immunity to bacillus phage W. J. gen. Microbiol. $18,198$.

Roti, N. G., Lively, D. H. \& Howge, H. M. (1955). Influence of oxygen uptake and age of culture on sporulation of Bacillus anthracis and Bacillus globigi. J. Bact. 69, 455.

Sterne, M. (1937). The effect of different carbon dioxide concentrations on the growth of virulent anthrax strains. Onderstepoort J. vet. Sci. 9, 49.

STERne, M. (1938). Variation in the colony form of the anthrax bacillus. Onderstepoort $J$. vet. Sci. 10, 245.

Thorne, C. B., Gomez, C. G. \& Housewright, R. D. (1952). Synthesis of glutamic acid and glutamyl polypeptide by Bacillus anthracis. II. The effect of carbon dioxide on peptide production on solid medium. J. Bact. 63, 363. 